OPEN ACCESS

Edited by:

Arshan Nasir,

COMSATS University Islamabad,

Pakistan

Reviewed by:

Bob Gordon Blasdel,

Vesale Pharma, Belgium

Andrei A. Zimin,

Institute of Biochemistry

and Physiology of Microorganisms

(RAS), Russia

*Correspondence:

Shuang-yong $X_{U}$

xus@neb.com

${ }^{\dagger}$ These authors have contributed equally to this work

Specialty section:

This article was submitted to

Virology,

a section of the journa

Frontiers in Microbiology

Received: 27 January 2019 Accepted: 07 March 2019

Published: 29 March 2019

Citation:

Flodman K, Tsai R, Xu MY, Corrêa IR Jr, Copelas A, Lee Y-J, Xu M-Q, Weigele P and Xu S-y (2019)

Type II Restriction of Bacteriophage DNA With 5hmdU-Derived Base

Modifications.

Front. Microbiol. 10:584. doi: 10.3389/fmicb.2019.00584

\section{Type II Restriction of Bacteriophage DNA With 5hmdU-Derived Base Modifications}

\author{
Kiersten Flodmant, Rebecca Tsait, Michael Y. Xut, Ivan R. Corrêa Jr., Alyssa Copelas, \\ Yan-Jiun Lee, Ming-Qun Xu, Peter Weigele and Shuang-yong Xu*
}

New England Biolabs, Inc., Ipswich, MA, United States

To counteract bacterial defense systems, bacteriophages (phages) make extensive base modifications (substitutions) to block endonuclease restriction. Here we evaluated Type II restriction of three thymidine ( $T$ or 5 -methyldeoxyuridine, $5 \mathrm{mdU}$ ) modified phage genomes: Pseudomonas phage M6 with 5-(2-aminoethyl)deoxyuridine (5-NedU), Salmonella phage Vil (Vi1) with 5-(2-aminoethoxy)methyldeoxyuridine (5-NeOmdU) and Delftia phage phi W-14 (a.k.a. $\Phi \mathrm{W}$-14) with $\alpha$-putrescinylthymidine (putT). Among $>200$ commercially available restriction endonucleases (REases) tested, phage M6, Vil, and phi W-14 genomic DNAs (gDNA) show resistance against 48.4, 71.0, and 68.8\% of Type II restrictions, respectively. Inspection of the resistant sites indicates the presence of conserved dinucleotide $\mathrm{TG}$ or $\mathrm{TC}$ (TS, $\mathrm{S}=\mathrm{C}$, or $\mathrm{G}$ ), implicating the specificity of TS sequence as the target that is converted to modified base in the genomes. We also tested a number of DNA methyltransferases (MTases) on these phage DNAs and found some MTases can fully or partially modify the DNA to confer more resistance to cleavage by REases. Phage M6 restriction fragments can be efficiently ligated by T4 DNA ligase. Phi W-14 restriction fragments show apparent reduced rate in E. coli exonuclease III degradation. This work extends previous studies that hypermodified $\mathrm{T}$ derived from $5 \mathrm{hmdU}$ provides additional resistance to host-encoded restrictions, in parallel to modified cytosines, guanine, and adenine in phage genomes. The results reported here provide a general guidance to use REases to map and clone phage DNA with hypermodified thymidine.

Keywords: Type II restriction and modification, 5hmdU-derived nucleotide modification, Pseudomonas bacteriophage (phage) M6, Salmonella phage Vil, Delftia phi W-14, phage therapy

\section{INTRODUCTION}

Type II restriction and modification (R-M) systems in bacteria encode restriction endonucleases (REases) to destroy invading foreign DNA in phage infection and acquisition of mobile genetic elements (Smith and Wilcox, 1970; Landy et al., 1974, reviewed in Pingoud et al., 2016). To gain an upper hand in the biowarfare, bacteriophages (phages) utilize DNA base modifications [or nucleotide (nt) substitutions] to counteract host-encoded Type II restrictions (Huang et al., 1982; Kruger and Bickle, 1983; Miller et al., 1985; Kulikov et al., 2014; Tsai et al., 2017; Lee et al., 2018). Extensive non-canonical nt substitutions have been reported for all four bases in DNA: for example, 
5-methylcytosine $(5 \mathrm{mC})$ replacing all $\mathrm{C}$ in phage XP12 genome (Feng et al., 1978), 5-glucosylated-hydroxymethylcytosines (5gmC) in phage T4 (Gold and Schweiger, 1969), deoxyarchaeosine $\left(\mathrm{dG}^{+}\right)$in phage $9 \mathrm{~g}$ (Thiaville et al., 2016; Tsai et al., 2017), $\alpha$-putrescinylthymidine (putT) in phi W-14 (Kelln and Warren, 1973; Kropinski et al., 1973), N6methyladenine $(6 \mathrm{~mA})$ in some phages encoding frequent adenine methyltranferases (MTases) (Drozdz et al., 2012; Murray et al., 2018), and 5-hydroxymethyluridine (5hmdU) in Bacillus phage SP8 and SPO1 (Stewart et al., 2009, reviewed in Weigele and Raleigh, 2016). Non-canonical nt substitutions can be introduced during DNA replication through modified dNTP (e.g., 5hmCTP, 5 hmdUTP). Further base modification can be carried out postreplicationally by phage-encoded enzymes such as MTases, DNA glycosyltranferases, and alkylamine transferases. In some cases, phage DNA is partially modified by host-encoded enzymes, such as Dcm (methylation of CCWGG to C5mCWGG) and Dam methyltransferases (methylation of GATC to G6mATC), or other MTases during phage DNA replication. Phage T4 DNA modified with $5 \mathrm{gmC}$ is resistant to many Type II REases that recognize GC-containing sequences (Huang et al., 1982). Phage $9 \mathrm{~g}$ DNA with the $\mathrm{dG}^{+}$modification is resistant to $\sim 71 \%$ of Type II restriction specificities with GC sequences (Tsai et al., 2017). In a limited Type II restriction study of phage phi W-14 genome containing putT, 17 out of 32 REases tested were blocked by the base modification (Miller et al., 1985). The additional positive charges from the side chain of putT likely interfere with restriction enzyme tracking process due to altered local DNA structure since the cleavage efficiency of some REases with only GC sequence was also impaired. Phi W-14 genomic DNA is packaged more compactly in phage head than T4 (Scraba et al., 1983). Phage SPO1 genomic DNA with 5hmdU substitutions is fully resistant to 4 out of 30 Type II restrictions $(\sim 13.3 \%)$ and partially resistant (i.e., slower cleavage in $1 \mathrm{~h}$ digestion) to 17 out of 30 REases tested (56.7\%) (Huang et al., 1982; Vilpo and Vilpo, 1995). DNA duplex oligos with the 5hmdU substitution display reduced melting temperature (Tm) and altered backbone flexibility when passing through nanopores (Carson et al., 2016).

Two new base modifications, 5-(2-aminoethyl)deoxyuridine (5-NedU) and 5-(2-aminoethoxy)methyldeoxyuridine (5$\mathrm{NeOmdU})$ were recently discovered in the genomes of Pseudomonas phage M6 and Salmonella phage ViI (Vi1) (Lee et al., 2018). Hypermodified Pseudomonas phage DNAs were shown to be resistant to Type II restriction. Phage M6 and ViI encode a modification gene cluster in their genomes for the production of $5 \mathrm{hmdU}$ and the enzymes responsible for subsequent reactions to add the desired chemical groups (Lee et al., 2018). It has been predicted that these phages also encode their own primase, DNA polymerase/clamp loader protein/sliding clamp holder protein, DNA ligase, and RNase $\mathrm{H}$, all of which displaying specialized properties to incorporate modified dNTP intermediate during replication. The three phages M6, ViI, and phi W14 containing hypermodified thymidine bases are thought to utilize the common intermediate $5 \mathrm{hmdU}$. 5hmdU is incorporated into DNA, then phosphorylated by a 5 hmdU DNA kinase, and further modified by alkylamine transferases and other associated enzymes. Not all thymidines in the genome are replaced by $5 \mathrm{hmdU}$; in addition to the hypermodified base, these phage DNAs may also carry regular base $\mathrm{T}$ and 5hmdU. Bioinformatic prediction of enzymes involved in phage nucleotide hypermodifications has provided abundant information on gene clusters and biosynthetic pathways (Iyer et al., 2013).

The goal of this work is to examine Type II restrictions of modified DNA in phage M6, ViI, and phi W-14 genomes. We performed restriction digestions of these three gDNAs to verify their resistant level in vitro. We also analyzed the resistant sites for any conserved sequence motifs to shed light on possible modification site specificity. Furthermore, we introduced additional base modifications in their DNA by treatment with cytosine or adenine MTases to generate two types of base modifications (for instance in M6 DNA, a combination of $5 \mathrm{mC}$ and $5-\mathrm{NedU}$, or $6 \mathrm{~mA}$ and $5-\mathrm{NedU})$. We also examined the ligation efficiency of phage DNA restriction fragments and tested two exonuclease activity on the modified DNA. This work provides basic information on restriction of T-modified DNA and further our understanding of the co-evolution relationship of host and hypermodified phage genomes. Study of highly modified phage genomes may have impact in phage therapy.

\section{MATERIALS AND METHODS}

\section{Phage DNA Purification and Restriction Digestions}

REases, MTases, DNA ligase, DNA nuclease, and phosphatase, Proteinase $\mathrm{K}$, exonuclease, and repair enzyme hSMUG1 were provided by New England Biolabs (NEB). Phage particles were purified by $\mathrm{CsCl}$ gradient method and phage DNA purified by phenol- $\mathrm{CHCl}_{3}$ extraction, and ethanol precipitation (Sambrook et al., 1989). Due to poor phage titer of M6 phage, phage infection and propagation were carried out on solid growth medium and phage lysates were pooled from multiple plates. NEBcutter V2.1 software (Vincze et al., 2003) was used to generate restriction patterns of phage DNA with the assumption of no base modification. We used excess of REases in restriction digestions ( 5 to $40 \mathrm{U}$ to cleave 0.25 to $0.5 \mu \mathrm{g}$ phage DNA) in $50 \mu \mathrm{l}$ total volume incubated at the recommended temperature for $1 \mathrm{~h}$ (e.g., $5 \mu \mathrm{l}$ of REases for low concentration enzyme supplied at $1000 \mathrm{U} / \mathrm{ml}, 2 \mu \mathrm{l}$ of REase for high concentration REase supplied at $20,000 \mathrm{U} / \mathrm{ml}$ ). Digested DNAs were analyzed by agarose gel electrophoresis. The DNA cleavage patterns were compared to NEBcutter-generated restriction patterns to determine digestion results as complete (c), partial (p), very partial (vp), or resistant (x) to digestions. For digestion of viral DNA with glycosylase and AP endonuclease, DNA was first incubated with hSMUG1 for $1 \mathrm{~h}$, and then treated with Escherichia coli endonuclease VIII.

\section{Methylation and Challenge With REases to Check Methylation Level}

Phage DNA was methylated by treatment with excess DNA MTase and methyl-donor SAM in the recommended 
buffer for $2 \mathrm{~h}$. Following Proteinase $\mathrm{K}$ treatment and spin column purification, the methylated DNA was digested by cognate or non-cognate REases to evaluate the degree of resistance to restriction.

\section{Methylation and Determination of Base Compositions by Liquid Chromatography-Mass Spectrometry (LC-MS)}

Phage DNA was methylated by the frequent MTases M.EcoGII (adenine methyltransferase), M.SssI (CpG methyltransferase), M.CviPI (GpC methyltransferase) for 2-4 h with methyl donor SAM. After Proteinase K treatment, the DNA was precipitated in ethanol, dried and resuspended in a buffer for nuclease degradation. DNA samples $(5 \mu \mathrm{g})$ were digested to nucleosides by treatment with the Nucleoside Digestion Mix (NEB, M0649S) overnight at $37^{\circ} \mathrm{C}$. Nucleoside analysis was performed on an Agilent LC/MS System 1200 Series instrument equipped with a G1315D diode array detector and a 6120 Single Quadrupole Mass Detector operating in positive (+ESI) and negative (-ESI) electrospray ionization modes. LC was carried out on a Waters Atlantis T3 column $(4.6 \mathrm{~mm} \times 150 \mathrm{~mm}, 3 \mu \mathrm{m})$ with a gradient mobile phase consisting of $10 \mathrm{mM}$ aqueous ammonium acetate ( $\mathrm{pH}$ 4.5) and methanol. MS data acquisition was recorded in total ion chromatogram (TIC) mode. Each nucleoside was identified as follows: $\mathrm{dC}[\mathrm{M}+\mathrm{H}]^{+} 228.1$ and $[\mathrm{M}-\mathrm{H}]^{-}$226.2; $\mathrm{dG}[\mathrm{M}+\mathrm{H}]^{+} 268.1$ and $[\mathrm{M}-\mathrm{H}]^{-}$266.1; $\mathrm{dT}[\mathrm{M}+\mathrm{H}]^{+} 243.1$ and $[\mathrm{M}-\mathrm{H}]^{-}$241.1; dA $[\mathrm{M}+\mathrm{H}]^{+} 252.1$ and $[\mathrm{M}-\mathrm{H}]^{-}$250.1; $5 \mathrm{mdC}[\mathrm{M}+\mathrm{H}]^{+} 242.1$ and $[\mathrm{M}-\mathrm{H}]^{-} 240.2 ; 6 \mathrm{mdA}[\mathrm{M}+\mathrm{H}]^{+}$ 266.1 and $[\mathrm{M}-\mathrm{H}]^{-}$264.1; 5hmdC $[\mathrm{M}-\mathrm{H}]^{-}$257.0; 5-NeOmdU $[\mathrm{M}+\mathrm{H}]^{+} 302.1$ and $[\mathrm{M}-\mathrm{H}]^{-} 300.1 ; \alpha$-putT $[\mathrm{M}+\mathrm{H}]^{+} 329.2$ and $[\mathrm{M}-\mathrm{H}]^{-}$327.2; putT-dC $[\mathrm{M}+\mathrm{H}]^{+} 618.3$ and $[\mathrm{M}-\mathrm{H}]^{-}$ 616.2; and putT-dG $[\mathrm{M}+\mathrm{H}]^{+} 658.2$ and $[\mathrm{M}-\mathrm{H}]^{-}$656.1. The relative abundance of each nucleoside was determined by dividing the UV absorbance by the corresponding extinction coefficient at $260 \mathrm{~nm}$.

\section{RESULTS}

\section{Restriction of Phage M6, Vil, and phi W-14 Genomic DNA}

To find out the resistance level, we carried out restriction digestions for phage M6, ViI, and phi W-14 genomic DNA. The chemical structure of the modified bases discussed in this work is shown in Supplementary Figure 1. It was unknown beforehand how many units are required for complete digestion of each modified DNA since the unit definition is typically done on phage $\lambda$ or pBR322 DNA by the manufacturer. We used phage $\lambda$ and pTYB2 DNA for control digestions to validate REases that are active, but not able to cleave modified DNA. The restriction of modified phage DNA was repeated at least once to confirm reproducibility. We grouped restriction results into four categories: complete, partial, very partial (most of the substrate DNA remains intact, only a few weak bands visible), and resistant as compared to computer generated banding patterns. The results are shown in Figures 1A-C and Table 1. Phage M6, ViI, and phi W-14 DNAs are resistant to approximately 48.4, 71.0, and $68.8 \%$ of Type II restrictions, as compared to phage $9 \mathrm{~g}$ DNA $\left(\mathrm{dG}^{+}\right.$modification) resistance to nearly $71 \%$ REases tested. The individual restriction results for three genomic DNAs are shown in Supplementary Tables 1-3. Phage M6 DNA is completely resistant to FspI (TGCGCA) and SacI (GAGCTC ) restriction, most likely due the modified $\mathrm{T}$ in $\mathrm{TG}$ and $\mathrm{TC}$ dinucleotide in both strands (see below for more resistant site analysis). Phage ViI DNA is resistant to restriction by BspHI (TCATGA), ClaI (ATCGAT), and NdeI (CATATG). Phi W-14 DNA is resistant to restriction by Hpy188III (TCNNGA) and HpyCH4V (TGCA) probably due to the modified bases in TG or TC dinucleotides in both strands. In some cases, phage DNA is also partially or completely resistant to REases that cleave target sites with 4-6 AT bp (see Supplementary Tables 1-3). We concluded that the longer side-chain modifications of phages ViI and phi W-14 DNAs are more effective at blocking Type II restriction than is the smaller aminoethyl group of phage M6 DNA. However, 5-NedU shows better resistance than phage DNA with 5hmdU alone (Vilpo and Vilpo, 1995). The partial positive charges of the side chain in the major groove of DNA may affect the indirect read out of target sequence by REases. The phage DNA sensitivity to Type II restriction is also shown in "pie" charts (Supplementary Figure 2). Since most of the restriction reactions were carried out with excess enzymes in an overdigestion protocol, we cannot rule out the possibility that some very partial digestions are caused by relaxed "star" activity (restriction enzyme "star" activity can cleave target sites with 1-2 bp off from the canonical sites) (Robinson and Sligar, 1993). Engineered high-fidelity REases were used where available to minimize "star" activity (Vasu et al., 2013). Thus, the resistance level might be underestimated compared to the in vivo restriction level. In vivo restriction gene expression is tightly regulated by transcription factors such as the $\mathrm{C}$ (controller) protein to prevent self-restriction (Tao and Blumenthal, 1992; Sawaya et al., 2013).

There are a number of REases that recognize and cleave target sites with GC bp sequence only. Interestingly, they can cut $\lambda$ and plasmid (pTYB2) DNA; but are unable to cleave M6 and phi W-14 DNA (Supplementary Figures 6A,B). We speculate that these REases are extremely sensitive to the nearby base modifications since the probability of TG dinucleotide $5^{\prime}$ to the ApaI (GGGCC/C) and PspOMI (G/GGCCC) sites is only 0.25 . Similarly, the probability of TG dinucleotide $5^{\prime}$ to the NarI (GG/CGCC) and PluTI (GGCGC/C) is 0.25. NarI and PluTI partially digested a single site plasmid pTYB2 as two sites are probably required for efficient digestion. This group of enzymes include Type IIE and IIF that requires a secondary site (effector site) and extensive looping and enzyme complex interaction (enzyme dimers or tetramers bound to two sites separated by a certain distance) (Roberts et al., 2003). Phi W14 genomic DNA is resistant or partially resistant to ApaI, NaeI (GCC/GGC), NgoMIV (G/CCGGC), NotI (GC/GGCCGC), or PspOMI digestion (Supplementary Figure 6B). The presence of TG dinucleotides (e.g., tGCCGGC) in the flanking sequence may play a role in the resistance, but it cannot explain all resistant sites. 


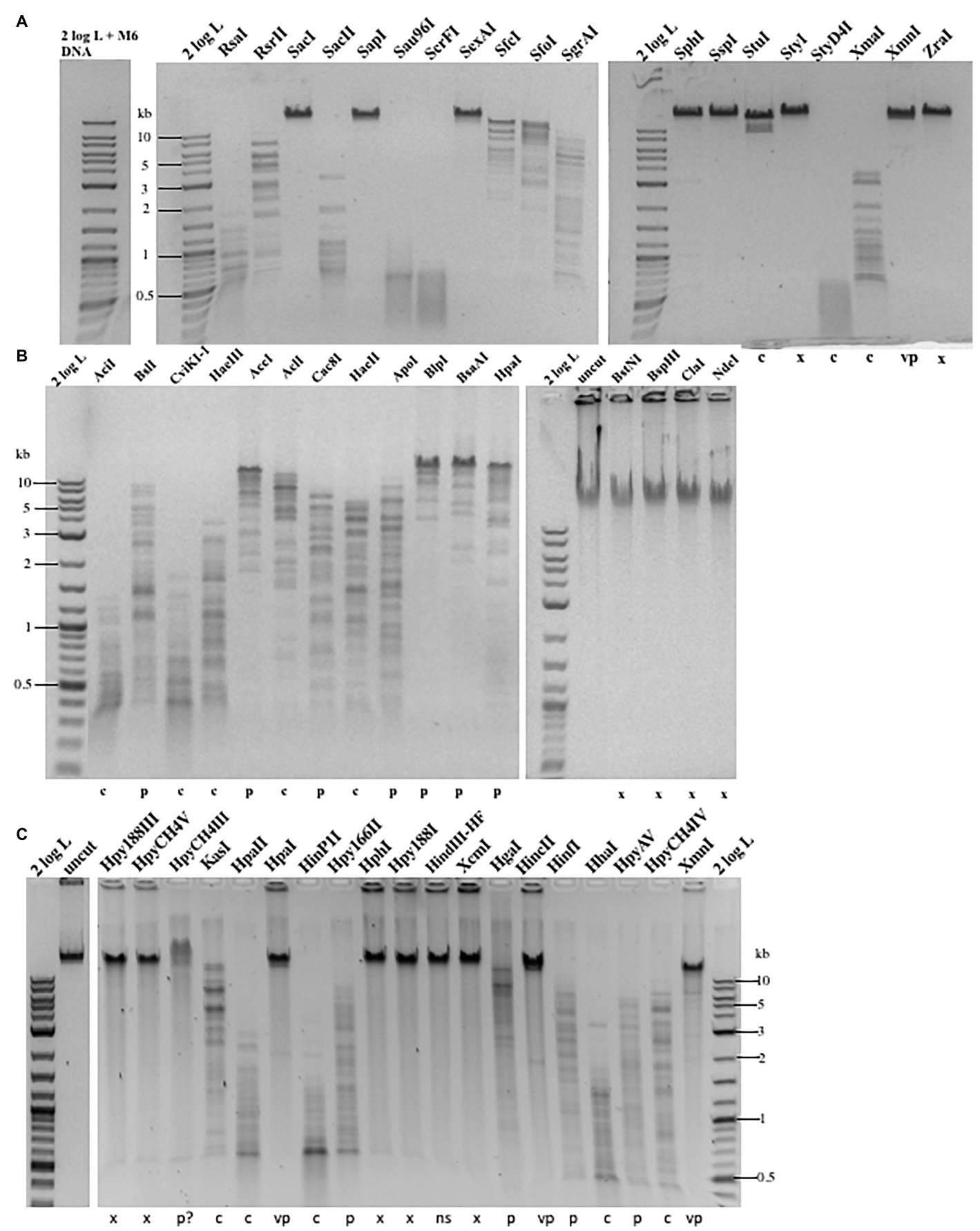

FIGURE 1 | Representative examples of Type II restriction of phage gDNA. (A) Phage M6 DNA digested with 19 REases and analyzed by agarose gel electrophoresis. X, resistant to restriction; C, complete digestion; $C^{*}$, additional fragments observed owing to star activity; P, partial digestion; VP, very partial digestion (only a few weak bands detected); 2 log DNA ladder (0.1-10 kb). Phage M6 DNA is resistant to restriction by Sacl (GAGCTC), Sapl (GCTCTTC), SexAl

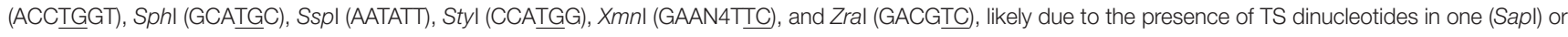
both strands. Sspl site with six Ts in the recognition sequence is also resistant. The restriction results are summarized in Supplementary Table 1. The computer-generated restriction patterns by NEBCutter are shown in Supplementary Figures 3-5. (B) Representative examples of restriction digestions of phage Vil gDNA. The Vil DNA is resistant to restriction by BstNI (CCTGG), BspHI (TCATGA), Clal (ATCGAT), and Ndel (CATATG), likely due to the presence of modified T in TS (TG or TC) dinucleotides in one or both strands. The restriction results are summarized in Supplementary Table 2. (C) Representative examples of phi W-14 gDNA digested by 19 REases. X, resistant; C, complete digestion; P, partial digestion; VP, very partial digestion; NS, no restriction sites present (as internal negative control); P?, DNA bound and slightly shifted with some smearing; Phi W-14 DNA is resistant to restrictions by Hpy 188 III (TCNNGA), HpyCH4V (TGCA), Hpal (GTTAAC), Hphl (GGTGA), Hpy188I (TCNGA), Xcml (CCAN9TGG), Hincll (GTYRAC), Hinfl (GANTC), and Xmnl (GAAN4TC). The phi W-14 DNA is partially resistant to HpyCH4III (ACNGT) since the probability of having TS sequence with immediate flanking $3^{\prime}$ nt in ACNGTS is 0.5 and the chance of having ACTGT is 0.25 . The phage DNA is largely resistant to Hpal (GTTAAC) with $t G$ and $4 T$ s in both strands. The restriction results are summarized in Supplementary Tables 1-3. 
TABLE 1| Type |l restriction of phage M6, Vil, and phi W-14 genomic DNA.

\begin{tabular}{lrrr}
\hline Cleavage status & M6 & Vil & Phi W-14 \\
\hline Complete & $33.7 \%$ & $8.3 \%$ & $10.7 \%$ \\
Inconclusive* & $1.6 \%$ & $2.7 \%$ & $0.9 \%$ \\
Partial & $16.3 \%$ & $18.0 \%$ & $19.6 \%$ \\
Very partial** & $7.9 \%$ & $6.9 \%$ & $8.4 \%$ \\
Resistant & $40.5 \%$ & $64.1 \%$ & $60.4 \%$ \\
Very partial + resistant & $48.4 \%$ & $71.0 \%$ & $68.8 \%$ \\
\hline
\end{tabular}

* Inconclusive: restriction fragments too large (>10 kb) to be clearly resolved in 0.8 $1 \%$ agarose gel. **Very partial: most of the genomic DNA remains intact and only a few weak bands were detected.

\section{Conserved Sequence Motif Among the Resistant Sites in Phage DNA}

It has been proposed that M6, ViI, and phi W-14 phages utilize phage-encoded DNA polymerases and a 5hmdUTP, dATP, dCTP, and dGTP deoxynucleotide pool for DNA replication, thus replacing all $\mathrm{T}$ with $5 \mathrm{hmdU}$ (Neuhard et al., 1980). Further base modifications can occur post-replicationally on the hydroxymethyl moiety of $5 \mathrm{hmdU}$ via a phosphorylated intermediate by the action of a 5hmdU DNA kinase (5HMUDK). It is not known whether the modification site is random or has certain sequence specificity. When the resistant sites were analyzed we observed a predominant sequence motif of TG, TC, TG+TC, or TS+TN dinucleotide. Table 2 shows that 44 out of 77 resistant sites $(57.1 \%)$ contain a TG, TC, or TG+TC sequence in phage M6 DNA, while $58.3 \%$ of the resistant sites in phage ViI contain the TS motif. The frequency of TS sequence in resistant sites is slightly lower in phage phi W-14 DNA at $49.6 \%$. These numbers are probably underestimated since they do not include the flanking sequence $\mathrm{T}$ outside of restriction sites (for example tGCCGGC with a TG dinucleotide). In the restriction analysis of these three phage DNAs, the majority of the resistant sites contain TS dinucleotide in combination with another TT
TABLE 2 | Frequency of dinucleotide in the resistant sites among the phage genomic DNA.

\begin{tabular}{|c|c|c|c|}
\hline \multicolumn{4}{|c|}{ TN dinucleotides in the resistant sites* } \\
\hline & Phage M6 & Phage Vil & Phi W-14 \\
\hline TG & 26 & 28 & 29 \\
\hline TC & 5 & 38 & 24 \\
\hline TC, TG & 13 & 15 & 15 \\
\hline TG, TA & 3 & 3 & 3 \\
\hline $\mathrm{TG}, \Pi \mathrm{T}$ & 4 & 3 & 4 \\
\hline TG, TN & 7 & 7 & 10 \\
\hline $\mathrm{TC}, \mathrm{TT}$ & 5 & 10 & 6 \\
\hline TC, TA & 0 & 3 & 3 \\
\hline $\mathrm{TC}, \mathrm{TN}$ & 1 & 10 & 9 \\
\hline Tा & 0 & 0 & 0 \\
\hline TA & 1 & 8 & 7 \\
\hline $\mathrm{TN}$ & 3 & 4 & 8 \\
\hline ТT, ТA & 1 & 2 & 1 \\
\hline TT, TN & 0 & 1 & 0 \\
\hline $\mathrm{TA}, \mathrm{TN}$ & 0 & 2 & 3 \\
\hline TC, TG, TT & 3 & 4 & 4 \\
\hline $\mathrm{TA}, \mathrm{TC}, \mathrm{TN}$ & 1 & 1 & 2 \\
\hline $\mathrm{TA}, \mathrm{TT}, \mathrm{TN}$ & 0 & 0 & 3 \\
\hline GC sequence only** & 4 & $?$ & 6 \\
\hline Total & 77 & 139 & 137 \\
\hline
\end{tabular}

TN, N = any four nucleotides. TS = TG or TC. *In this resistant site analysis, most of the flanking sequences are excluded. ${ }^{* *} G C$ sequence only: a number of REases without $A / T$ in the recognition sequence cannot cleave phage M6 or phi W-14 DNA. But they are active in restriction of $\lambda$ or plasmid DNA (see examples in Supplementary Figure 6). The resistance could be partially due to the $5^{\prime}$ flanking sequence $T$ and negative impact on enzyme tracking process on modified DNA. Highlighted sequences containing TS dinucleotides.

or TA dinucleotide. This suggests that the 5hmdU DNA kinase involved in the phosphorylation of $5 \mathrm{hmdU}$ very likely shows the same preference for the TG or TC (TS) sequences. Consistent with the above observation, purified 5hmdU DNA kinase from

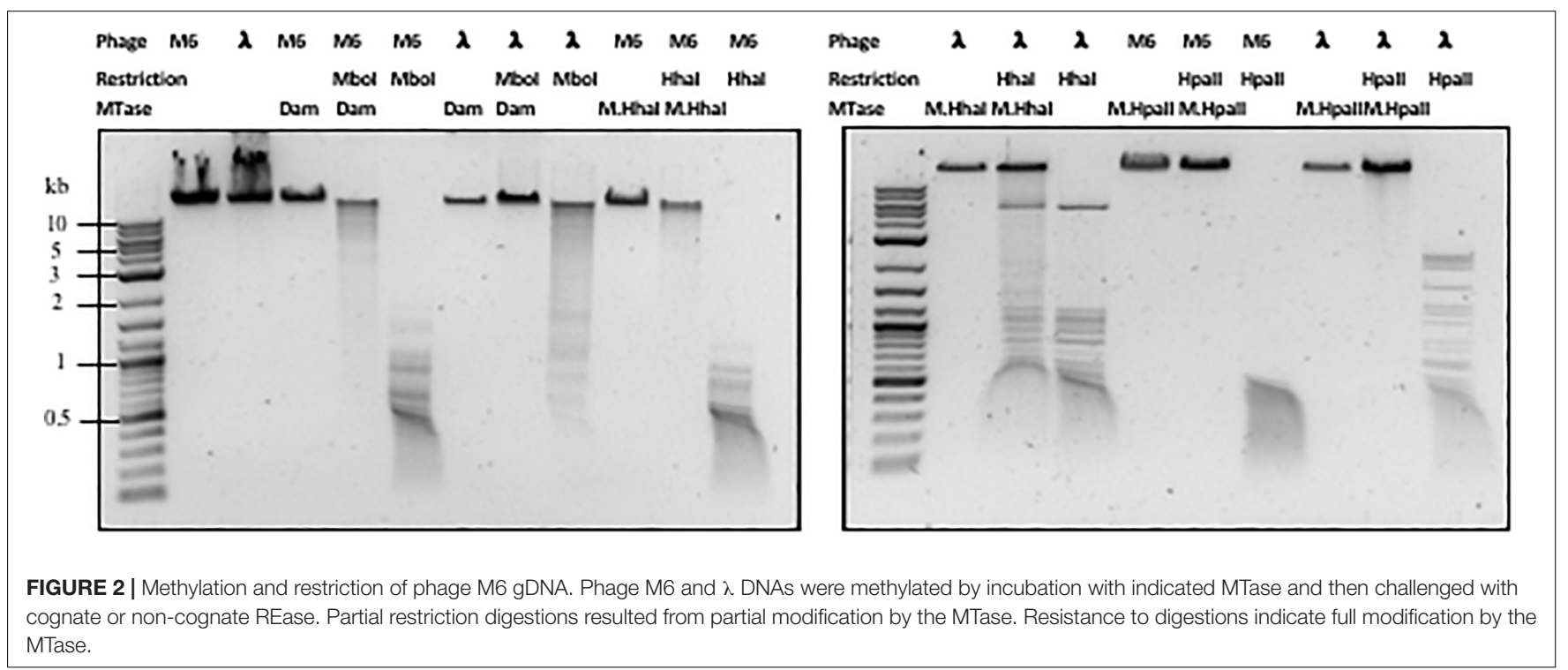


phage M6 can modify TG dinucleotides in phage SP8 genomic DNA containing $5 \mathrm{hmdU}$ (PW, unpublished result).

\section{Methylation of Phage M6 DNA to Generate 5mC- or 6mA-Modified DNA}

Next, we examined whether Pseudomonas phage M6 DNA can be further modified by C5-cytosine and adenine MTases. This experiment has two possible outcomes: (1) if M6 DNA can be further modified by these MTases, the double-modified DNA may be resistant to more Type II restrictions; (2) $5 \mathrm{mC}$ - and N6mA-modified DNA may be subjected to $5 \mathrm{mC}$-dependent restriction systems such as EcoK McrBC (Dila et al., 1990) and McrA (Mulligan and Dunn, 2008; Czapinska et al., 2018) or N6mA-dependent restriction system EcoK Mrr (Heitman and Model, 1987) and Pgl system found in Streptomyces, respectively (Hoskisson et al., 2015). Host-acquired modifications of phage genome by Type I MTases were discovered in the early days of molecular biology and phage genetics (Luria and Human, 1952; Bertani and Weigle, 1953; Luria, 1953). Over-expression of a Type II DNA MTase M.BsuM partially modified phage SP10 genome and increased the phage plating efficiency on restriction-proficient $\left(\mathrm{BsuMR}^{+}\right)$strain (Matsuoka et al., 2005). In this work we performed DNA methylation and subsequent restriction in vitro. After methylation reactions and proteinase $\mathrm{K}$ treatment, the phage M6 DNA was purified by spin column and subjected to restriction by the cognate REase or non-cognate endonuclease that is supposed to be blocked by the methylation. Figure 2 shows representative examples of methylation and restriction experiments. After M.CviPI (GpC methyltransferase) or M.HhaI methylation, the M6 DNA is largely resistant to HhaI (GCGC) restriction. M.HpaII and M.MspI can also fully modify M6 DNA and render the DNA resistant to HpaII (CCGG) and MspI (CCGG) restriction, respectively. M.SssI and M.AluI can partially modify the M6 DNA and provide partial resistance to HpaII or AluI (ACGT) restrictions. For the adenine MTases, Dam methyltransferase, M.EcoGII, and M.TaqI can partially modify the M6 DNA and provide partial resistance to MboI (GATC) and TaqI (TCGA) restriction. The methylation and restriction results are summarized in Table 3 . We concluded that phage M6 DNA can be further modified by C5-cytosine or adenine MTases, which provide additional protection against Type II restriction. The secondary nt modifications might be beneficial for using Pseudomonas lytic phages to combat multidrug resistant Pseudomonas infection.

\section{Base Composition Analysis of Methylated Phages Vil and phi W-14 DNA}

To estimate the level of methylation in phage ViI and phi W14 DNAs, we performed LC-MS analysis of the corresponding MTase-treated DNAs. Figure 3 shows that $\sim 28 \%$ of adenosines have been methylated to $6 \mathrm{~mA}$ in M.EcoGII-treated ViI genomic DNA. M.CviPI-treated ViI DNA gave rise to $\sim 7 \%$ of $5 \mathrm{mC}$. The composition of the naturally occurring 5-NeOmdU, 5-hmdU, and $\mathrm{T}$ in phage ViI genomic DNA were estimated at 43,7 , and $50 \%$, respectively. In a control experiment, M.EcoGII-mediated A to $6 \mathrm{~mA}$ conversion and M.CviPI-mediated $\mathrm{GpC}$ to $\mathrm{Gp} 5 \mathrm{mC}$ conversion in phage $\lambda$ DNA reached $\sim 93$ and $\sim 30 \%$, respectively (data not shown).

Base composition analysis of the EcoGII-treated phi W-14 genomic DNA indicated that $56 \%$ of adenosines were converted to $6 \mathrm{~mA}$ (Figure 4). The C5-cytosine MTases M.CviPI and M.SssI were capable of converting $8 \%$ and $12 \%$ of cytidines to $5 \mathrm{mC}$ in phi W-14 DNA, respectively. The naturally occurring putT in phage phi W-14 DNA was detected at approximately 48\%, which is consistent with the $\sim 50 \%$ putT reported in a previous work (Kropinski et al., 1973; Maltman et al., 1980) (note that total levels of putT reported here include the putT-G and putT$\mathrm{C}$ dinucleotides, which result from the incomplete digestion due to the presence of the putrescinyl group) (Figure 4). The reason for poor methylation by the C5 MTases on ViI and phi W-14 DNA is unknown. Poor cytosine methylation may provide certain advantage against $5 \mathrm{mC}$-dependent restriction systems such as BisI, McrBC, McrA, MspJI, and TaqI homologs (Cohen-Karni et al., 2011; Xu et al., 2016; Kisiala et al., 2018).

\section{Ligation of Restriction Fragments of Phages Vil and phi W-14 DNA}

In phage ViI DNA, approximately $43 \%$ of Ts have been replaced by $5-\mathrm{NeOmdU}$. The percentage of put $\mathrm{T}$ replacing $\mathrm{T}$ in phage phi W-14 was in the range of $47-48 \%$ (see Figure 4). We examined the ligation efficiency of restriction fragments from phage ViI and phi W-14 by T4 DNA ligase. NlaIII- (CATG/) and FatI- (/CATG) partially digested, or RsaI (GT/AC) completely digested ViI restriction fragments were ligated at $16^{\circ} \mathrm{C}$ overnight. The sticky ends of NlaIII and FatI fragments were efficiently ligated, whereas the blunt-ended RsaI fragments were ligated at a lower efficiency (Figure 5A). The Sau3AI- or MboI-digested (partial digestions) of phi $\mathrm{W}-14$ restriction fragments were ligated efficiently indicated by the appearance of large concatenated DNA after ligation. Lower ligation efficiency was observed for blunt-ended RsaI fragments (Figure 5B). We concluded that even though modified $\mathrm{T}$ could slow down restriction digestions by NlaIII and FatI for ViI genomic DNA, or by Sau3AI and MboI for phi W-14 DNA, the resulting restriction fragments can be efficiently ligated by T4 DNA ligase. The lower efficiency of RsaI fragment ligation is most likely due to the blunt-ended nature of the ligation (Sambrook et al., 1989; Tsai et al., 2017).

\section{Exonuclease Digestion of Vil and phi W-14 Genomic DNA}

We next examined exonuclease activity on phage M6, ViI and phi W-14 DNA. Two types of phage DNA restriction fragments were digested with different amount of $\lambda$ exonuclease or $E$. coli exonuclease III. Phage M6 and ViI restriction fragments were equally degraded by the two exonucleases (Supplementary Figures 7A,B). However, phi W-14 restriction fragments showed apparent slowed-down in exonuclease degradation (at 10-20 U range vs. $0.5 \mu \mathrm{g}$ DNA) (Supplementary Figure 7C). Unmodified 2-log DNA ladder is sensitive to $E$. coli exonuclease III and $\lambda$ exonuclease digestions (data not shown). The mechanism of phi W-14 DNA partial resistance to exonuclease digestion is still unknown. It was reported previously that the rate of 
TABLE 3 | Methylation and subsequent restriction challenge of methylated phage M6 DNA.

\begin{tabular}{|c|c|c|c|c|c|}
\hline \multicolumn{2}{|c|}{ Type of DNA MTase } & \multirow[t]{2}{*}{ Sequence modified } & \multirow{2}{*}{$\begin{array}{l}\text { REase used to } \\
\text { challenge DNA }\end{array}$} & \multirow[t]{2}{*}{ Methylation status } & \multirow{2}{*}{$\begin{array}{l}\text { Cleavage of gDNA } \\
\text { prior to methylation }\end{array}$} \\
\hline Phage M6 & 5mC MTase & & & & \\
\hline & M.Alul & AGCT & Alul & Partial & Partial \\
\hline & CpG (M.Sssl) & CG & Hpall & Partial & Complete \\
\hline & GpC (M.CviPI) & $\mathrm{GC}$ & Hhal & Complete & Complete \\
\hline & M.Haelll & GGCC & Haelll & Partial & Complete \\
\hline & M.Hhal & GCGC & Hhal & Partial & Complete \\
\hline & M.Hpall & CCGG & Hpall & Complete & Complete \\
\hline & M.Mspl & CCGG & Mspl & Complete & Complete \\
\hline & \multicolumn{5}{|l|}{ 6mA MTase } \\
\hline & Dam & GATC & Mbol & Partial & Complete \\
\hline & M.EcoGll & A & $\mathrm{Mbol}$ & Partial & Complete \\
\hline & M.Taql & TCGA & Taql & Partial & Complete \\
\hline
\end{tabular}

Highlighted sequences, complete methylation.

DNA hydrolysis by non-specific endonuclease of modified phage PBS1 (dT substituted by dU) was decreased by 14.3-fold, and hypermodified phage T4 DNA also shows slow-down in nuclease degradation (Huang et al., 1982).

\section{Digestion of Phage Vil and phi W-14 DNA With DNA Glycosylase and AP Endonuclease}

$5 \mathrm{hmdU}$ can be excised by DNA repair enzymes AlkA and Mug from E. coli, and by human SMUG1 (hSMUG1) and TDG to create AP sites (apurinic/apyrimidinic site), which can be further cleaved by AP endonucleases (Ulbert et al., 2004). Since ViI genomic DNA contains a small amount of $5 \mathrm{hmdU}$ we tested whether ViI and phi W-14 genomic DNA could be fragmented by hSMUG1 and AP endonuclease. Supplementary Figure 8 shows that a small amount of smearing of ViI gDNA after treatment with hSMUG1 and Endonuclease VIII, probably resulting from cleavage in the small percentage of $5 \mathrm{hmdU}$ in the genome. Phi $W-14$ and $\lambda$ DNA (a negative control) is quite resistant to the cleavage by the combination of these two enzymes. In the positive control sample, phage SP8 DNA (5hmdU substituted for T) was extensively hydrolyzed by hSMUG1 and Endonuclease VIII.

\section{DISCUSSION}

\section{Biological Function of Base Modification (nt Substitution)}

In bacterial host and phage coevolution, phage use extensive base modifications (nt substitutions) to protect its genome against host restrictions. The results presented here demonstrate that hypermodified $\mathrm{T}$ derived from $5 \mathrm{hmdU}$ can also efficiently protect phage genomes against Type II restrictions, in analogous manner to modified $\mathrm{Gs}$, such as $\mathrm{dG}^{+}$found in phage $9 \mathrm{~g}$ genome (Thiaville et al., 2016) and 2'-deoxy-7-amido-7-deazaguanosine (dADG) found in certain bacteria genomic islands (Yuan et al., 2018), to modified As, such as N6-(1-acetamido)-adenine in phage $\mathrm{Mu}$ genome (Hattman, 1979), to modified Cs, such as $5 \mathrm{gmC}$ in phage $\mathrm{T} 4,5 \mathrm{hmC}$ in phage T4gt, and $5 \mathrm{mC}$ in phage XP12 genome. Although not much in vivo restriction study has been carried out on T-hypermodified phages, it is very likely that there is a strong correlation between in vitro and in vivo restriction activity. Depending on the in vivo enzyme activity and level of restriction gene expression, restriction of phage infection can be in the range of $10^{2}-10^{6}$ fold (reviewed in Pingoud et al., 2016). In this work we focus on Type II restrictions in vitro. Resistance against Type I restriction has not been studied and we only tested one ATPdependent Type III restriction (EcoP15I, CAGCAG N25/). We hypothesize that phages M6, ViI, and phi W-14 may be resistant or partially resistant to Type I restriction as long as the restriction sites of these enzymes contain one or more TS dinucleotide sequence. $5 \mathrm{mC}$-dependent REases are not tested on the three phage DNA substrates.

To counter adenine or cytosine modifications of phage genomes, bacteria develop modification-dependent REases (MDRE) to specifically attack modified DNA (Fleischman et al., 1976; Raleigh et al., 1989). For example, the E. coli GmrSD endonuclease attacks $5 \mathrm{hmC}$ and $5 \mathrm{gmC}$ modified DNA (Bair and Black, 2007; He et al., 2015). We have not found MDREs against modified $\mathrm{T}$ or modified $\mathrm{G}$, but such enzymes might exist in nature. In addition, phages use anti-restriction proteins, small inhibitor proteins, DNA mimic protein to inhibit host-encoded REase (Rifat et al., 2008). Another likely function of modified bases is to help phage DNA packaging; for example, the positive charges of protonated $-\mathrm{NH}_{2}$ groups in the putrescinyl group of put T side chain helps counter balance the negative charges of the DNA backbone, thereby enhancing DNA structural flexibility and denser packing the DNA into the viral capsid (Scraba et al., 1983). In addition to enhanced DNA packing capability, modified bases have also been implicated in regulation of promoter strength and gene expression during initiation of DNA packaging into phage prohead (Greene et al., 1986). This has been demonstrated in phage P1 that the GATC sequences in the packaging site ( $p a c)$ are recognized and methylated by the phage-encoded Dam MTase triggering cleavage of pac sites and phage packaging initiation (Coulby and Sternberg, 1987; 


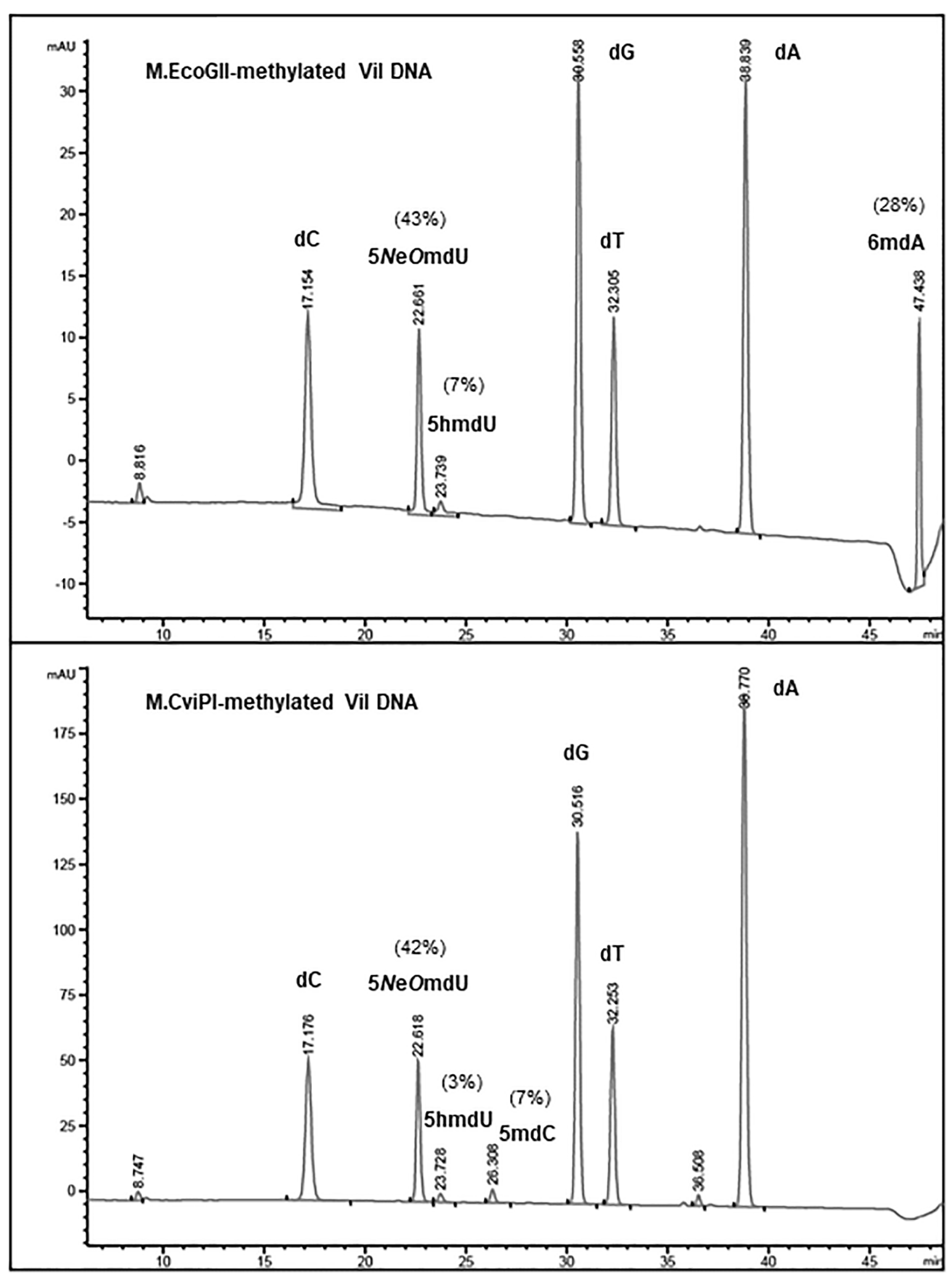

FIGURE 3 | Base composition analysis by LC-MS of M.EcoGll- or M.CviPI-methylated Vil gDNA. The distribution of thymine-derived bases 5-NeOmdU, 5hmdU, and dT were estimated at 43,7 , and $50 \%$ in phage Vil genome, respectively. The percentage of $6 \mathrm{~mA}$ generated by treatment with $\mathrm{M}$.EcoGll was approximately $28 \%$ of the total adenosines (top panel). The percentage of $5 \mathrm{mC}$ was only $7 \%$ after methylation of the phage Vil gDNA with the GpC methyltransferase M.CviPI (bottom panel). 


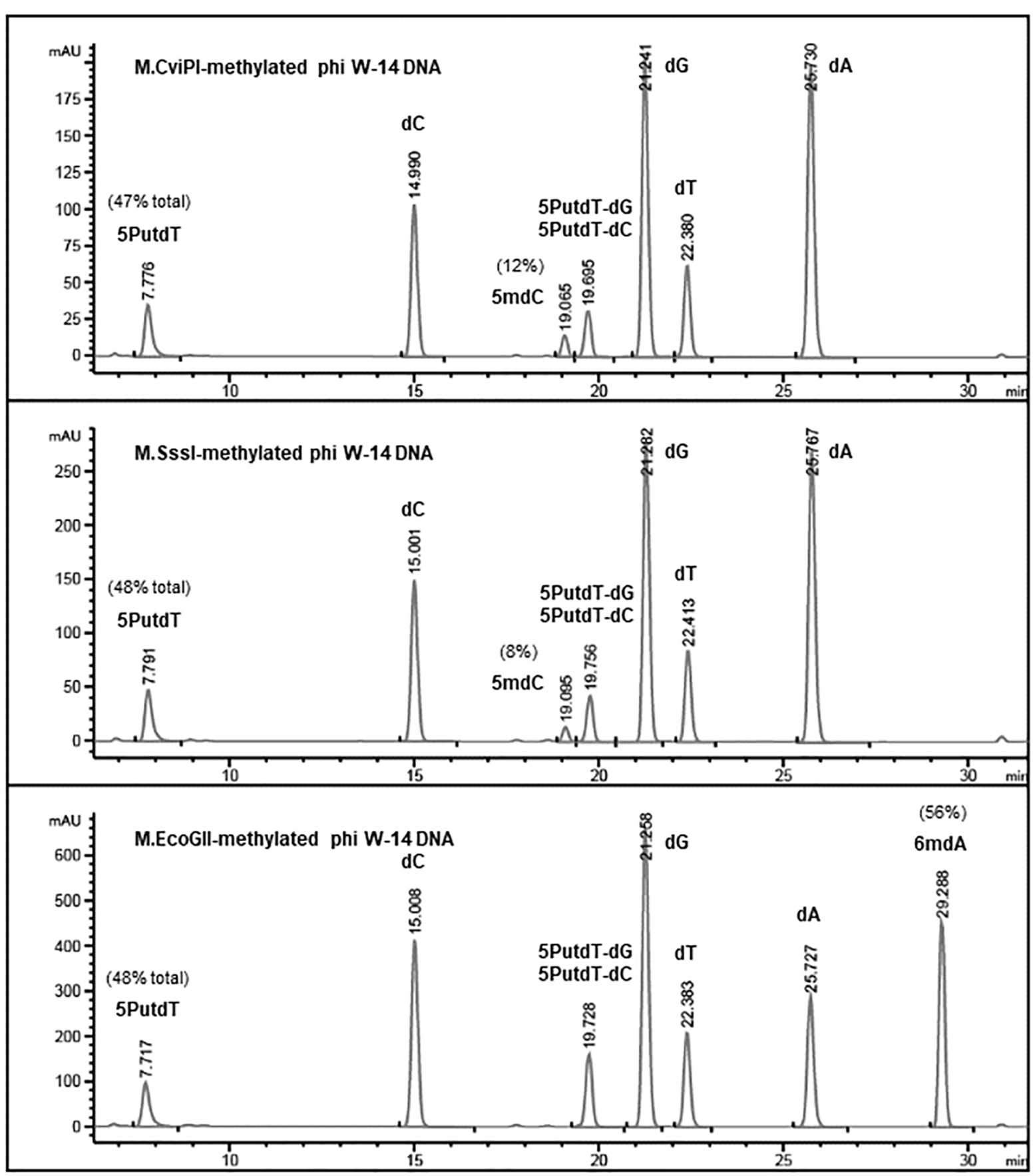

FIGURE 4 | Base composition analysis by LC-MS of M.CviPI-, M.Sssl-, and M.EcoGll-methylated phi W-14 genomic DNA. The percentage of 5mC was $~ 8$ and $\sim 12 \%$ after treatment with the GpC and CpG methyltransferases M.CviPI and M.Sssl, respectively. $6 \mathrm{~mA}$ levels reached $56 \%$ after methylation with M.EcoGll. The natural modified base putT was detected in the range of $47-48 \%$, in close agreement with previously published results ( $50 \%$ ). A small fraction of putT was present in the form putT-G and putT-C dinucleotides due to incomplete digestion of the phi W-14 DNA.

Sternberg and Coulby, 1990). The effect of modified Ts on promoter strength and transcription regulation remains to be studied for the three phages reported here.

Bacillus phage SPO1 genomic DNA wherein $>98 \%$ of Ts are replaced by $5 \mathrm{hmdU}$ is resistant or partially resistant to over $50 \%$ of Type II REases with $0-4$ Ts in the recognition sequences (Huang et al., 1982; Vilpo and Vilpo, 1995). Another important aspect of the non-canonical nucleotide in the genome is the regulation of viral gene expression: temporal differential expression of the early and late viral genes in transcription (Greene et al., 1986; Hoet et al., 1992). Phage M6 DNA carrying the modified base 5-aminoethyl which confers slightly higher 

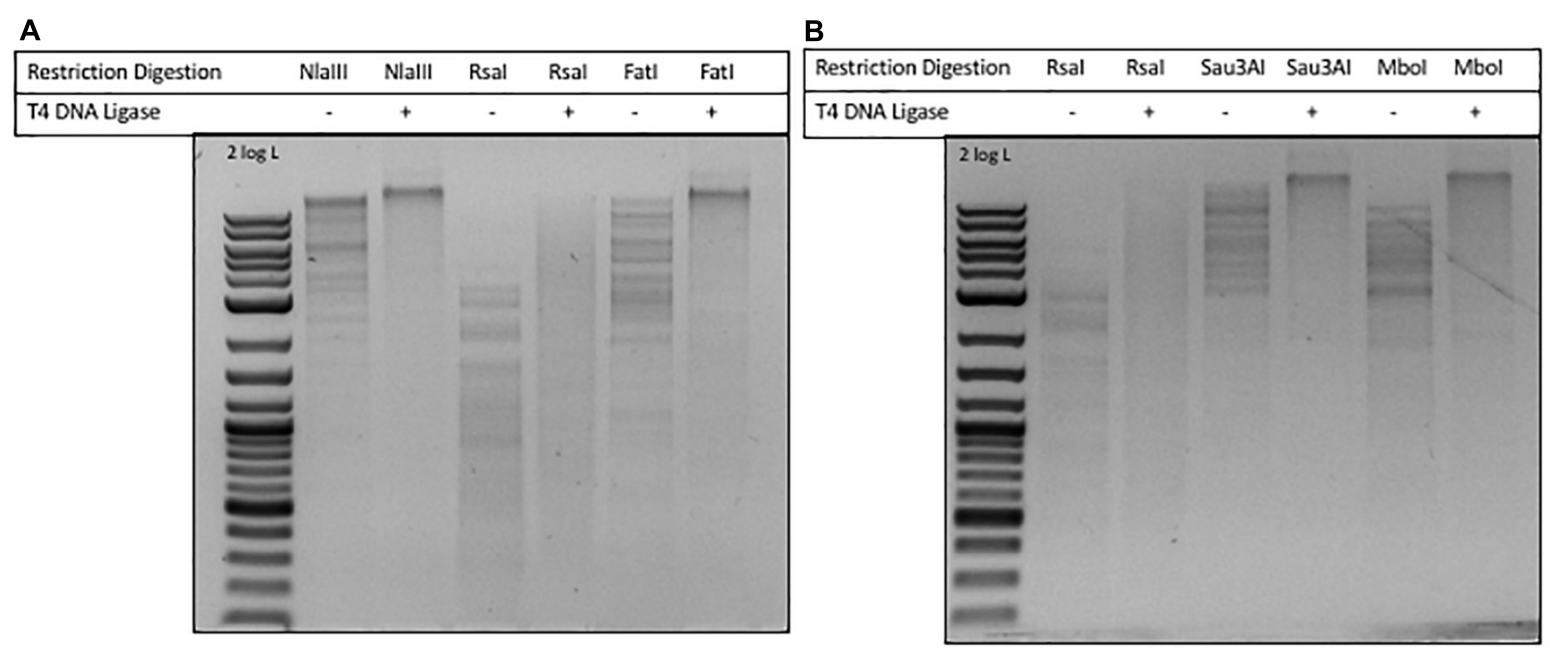

FIGURE $\mathbf{5}$ | Ligation of phages Vil and phi W-14 restriction fragments by T4 DNA ligase. (A) Ligation of phage Vil restriction fragments partially digested by Nlalll and Fatl, and completely digested by Rsal. Cleavage sites of REases: Nlalll (CATG/), 3' 4-base overhang; Rsal (GT/AC), blunt ends; Fatl (/CATG), 5' 4-base overhang. (B) Ligation of phage phi W-14 restriction fragments generated by Rsal, Sau3Al, and Mbol digestions. Cleavage sites of Rsal (GT/AC), blunt ends; Sau3Al (/GATC), and Mbol (/GATC), 5' 4-base overhang.

resistance $(48.9 \%$ complete and $15.8 \%$ partial resistance). More complex modifications, such as in phage ViI led to even higher resistance level $(\sim 71.0 \%)$. It is not clear how phages balance the need for base modification to become highly resistant to host-encoded restrictions and energy (ATP) consumption on making these base modifications and the ultimate evolutionary advantage in successful infection of bacterial hosts. Some Bacillus phage or prophage genomes encode frequent multi-specificity cytosine MTases (Xu et al., 1992, 1997; Schumann et al., 1995). Phage T2 and T4 encode an adenine MTase $\left(\mathrm{dam}^{+}\right)$ that methylates GATC sites to provide more resistance against REases with overlapping GATC sequence. T even phages provide examples of two types of base modifications $(6 \mathrm{~mA}+5 \mathrm{hmC}$ or $6 \mathrm{~mA}+5 \mathrm{gmC}$ ) in their genome (Schlagman and Hattman, 1983). We have not yet observed phage genomes having both modified cytosine and thymine perhaps because of the small sample size of the sequenced phage genomes. Phage $\lambda$ DNA contains some modified cytosine $(5 \mathrm{mC})$ and adenine $(6 \mathrm{~mA}$, $\sim 15 \%$ ) when the phage is propagated on $\mathrm{Dam}^{+} \mathrm{Dcm}^{+}$E. coli host. With advancement in DNA sequencing technology, single molecule SMRT sequencing and Nanopore sequencing might be able to sequence and identify more modifies bases in addition to N4mC and N6mA in DNA (Flusberg et al., 2010; Clark et al., 2012).

\section{MDRE in Pseudomonas Strains and Phage Therapy}

The Pseudomonas phage M6 DNA can be efficiently methylated by a few frequent C5-cytosine MTases to achieve double base modifications, which can provide more protection against Type II restrictions with $\mathrm{GC}$ recognition sequence. But the $5 \mathrm{mC}$ modifications also provide an opportunity for $5 \mathrm{mC}$-dependent restrictions. Some Pseudomonas genomes encode McrBC and
Mrr-like, and BisI-like enzymes (REBASE) that remain to be characterized.

A cocktail of Pseudomonas lytic phages has been successfully used to treat $P$. aeruginosa infections in animal models (Forti et al., 2018). The DNA restriction data presented here suggests clinicians should take into consideration of heavily modified phage genomes and host restriction systems on the success or failure of phage-based therapies.

\section{Conserved Sequence Motif in Resistant Sites}

Analysis of the resistant sites in the phage genomes revealed a conserved motif TG, TC, or TS, suggesting the modified Ts possess certain sequence specificity, which may have been conferred by phage DNA 5hmdU kinase that phosphorylates the base for further chemical modification. Understanding the enzymes involved in thymidine hypermodification in phage genomes is an active research topic in our lab (YJL, PW) (Lee et al., 2018). In support of the preferred TS specificity observed among the resistant sites, purified DNA 5hmdUMP kinase can phosphorylate the 5 hmdU base in phage DNA substrates (NcoI, CCATGG) (PW, unpublished result). For complete restriction digestion of hypermodified $\mathrm{T}$ phage DNA and cloning of certain genes (restriction fragments), Supplementary Tables 1-3 provide a useful guidance to choose among various commercially available restriction enzymes.

\section{CRISPR-Cas Associated Protein Cas4 Nuclease and Homing Endonucleases}

Both ViI and phi W-14 encode a three-gene cluster with predicted function in restriction (phage against phage superinfection). ORFs Vi01_137, 138, and 139 encode putative RNA-DNA 
and DNA-DNA helicase/ATPase, CRISPR-Cas associated protein Cas4 nuclease (Cas4 IA-ID, IIB superfamily), and ssDNA binding protein in the ViI genome. Similarly, a three-gene cluster in phi W-14 genome contains gp030, gp032, and gp031. But the exact function of the three proteins involved in DNA metabolism (restriction) is still unknown. Incidentally, phage ViI also encodes a superinfection exclusion protein (Vi01_111c) that may play a role in attenuation of other phage infections. ViI genome encodes one GIY-YIG superfamily endonuclease (Vi01_159c); and phi W-14 genome encodes two $\mathrm{HNH}$ endonucleases (gp143 and gp219). These endonucleases are probably homing endonucleases involved in insertion of intron into intronless target known as intron "homing" since there are no cognate MTase genes associated with the predicted endonucleases (reviewed in Stoddard and Belfort, 2010). Because of large recognition sequence of homing endonucleases (typically 16-30 bp), there is no need to encode cognate MTase for self-protection.

\section{Base $\mathrm{J}$ and $5 \mathrm{hmdU}$ in Eukaryotic Parasite, DNA Glycosylase/AP Endonuclease}

Base J (O-linked glucosylated thymine, $\beta$-D-glucosyl -deoxymethyluracil) in human pathogens Trypanosoma brucei, Trypanosoma cruzi, and Leishmania species, consisted of about $1 \%$ of total $\mathrm{T}$ in the genomes. The modified base $\mathrm{J}$ is an important regulatory epigenetic mark in trypanosomatids to influence gene expression. The JBP1/2 enzymes catalyze hydroxylation of thymine ( $\mathrm{Yu}$ et al., 2007), forming 5-hydroxymethyluracil (5hmdU), which is then glucosylated by the base J-associated glucosyltransferase (JGT). The presence of glucosylated 5hmdU has not been reported in phage genomes. DNA with base $\mathrm{J}$ modification is not a substrate for DNA repair enzyme AlkA and Mug of E. coli, and hSMUG1 and TDG (Ulbert et al., 2004). When phage genomes contain large number of 5 hmdU bases, the phage DNA is possibly subjected to DNA glycosylase cleavage. We show that phage ViI gDNA can be partially digested by hSMUG1 and Endonuclease VIII due to the presence of small amount of $5 \mathrm{hmdU}$ in the genome. But phi W-14 is fully resistant to hSMUG1 and endonuclease VIII; while phage SP8 genome with $5 \mathrm{hmdU}$ is heavily degraded

\section{REFERENCES}

Bair, C. L., and Black, L. W. (2007). A type IV modification dependent restriction nuclease that targets glucosylated hydroxymethyl cytosine modified DNAs. J. Mol. Biol. 366, 768-778. doi: 10.1016/j.jmb.2006.11.051

Bertani, G., and Weigle, J. J. (1953). Host controlled variation in bacterial viruses. J. Bacteriol. 65, 113-121.

Carson, S., Wilson, J., Aksimentiev, A., Weigele, P. R., and Wanunu, M. (2016). Hydroxymethyluracil modifications enhance the flexibility and hydrophilicity of double-stranded DNA. Nucleic Acids Res. 44, 2085-2092. doi: 10.1093/nar/ gkv1199

Clark, T. A., Murray, I. A., Morgan, R. D., Kislyuk, A. O., Spittle, K. E., Boitano, M., et al. (2012). Characterization of DNA methyltransferase specificities using single-molecule, real-time DNA sequencing. Nucleic Acids Res. 40, e29. doi: 10.1093/nar/gkr1146 by the two enzymes. The 5hmdU base is to be further modified to become resistant to host DNA glycosylases/AP endonucleases and REases such as in the case of phage M6, ViI and phi W-14. Alternatively, the 5hmdU-containing phages can only infect bacterial hosts deficient in AlkA- and Mug-like repair enzymes or by expression of phage-encoded enzyme inhibitors.

\section{DATA AVAILABILITY}

The datasets generated for this study are available on request to the corresponding author.

\section{AUTHOR CONTRIBUTIONS}

KF, RT, MX, IC, AC, and S-YX performed experimental work. M-QX, Y-JL, IC, PW, and S-YX contributed with ideas. S-YX wrote the manuscript with input from all the authors.

\section{FUNDING}

KF, RT, MX, and AC were supported by NEB's summer research and internship program. The financial support for this work and open access fee was provided by New England Biolabs, Inc.

\section{ACKNOWLEDGMENTS}

We thank Bill Jack and Rich Roberts for their critical comments on the manuscript, and Andy Gardner and Lise Raleigh for helpful discussions. We also thank Don Comb, Jim Ellard, Rich Roberts, Andy Gardner, Bill Jack, and Tom Evans for their guidance and support.

\section{SUPPLEMENTARY MATERIAL}

The Supplementary Material for this article can be found online at: https://www.frontiersin.org/articles/10.3389/fmicb. 2019.00584/full\#supplementary-material

Cohen-Karni, D., Xu, D., Apone, L., Fomenkov, A., Sun, Z., Davis, P. J., et al. (2011). The MspJI family of modification-dependent restriction endonucleases for epigenetic studies. Proc. Natl. Acad. Sci. U.S.A. 108, 11040-11045. doi: 10.1073/pnas. 1018448108

Coulby, J., and Sternberg, N. (1987). Bacteriophage P1 encodes its own dam methylase. Plasmid 17, 81.

Czapinska, H., Kowalska, M., Zagorskaite, E., Manakova, E., Slyvka, A., and Xu, S. Y. (2018). Activity and structure of EcoKMcrA. Nucleic Acids Res. 46, 9829-9841. doi: 10.1093/nar/gky731

Dila, D., Sutherland, E., Moran, L., Slatko, B., and Raleigh, E. A. (1990). Genetic and sequence organization of the mcrBC locus of Escherichia coli K-12. J. Bacteriol. 172, 4888-4900. doi: 10.1128/jb.172.9.4888-4900.1990

Drozdz, M., Piekarowicz, A., Bujnicki, J. M., and Radlinska, M. (2012). Novel nonspecific DNA adenine methyltransferases. Nucleic Acids Res. 40, 2119-2130. doi: 10.1093/nar/gkr1039 
Feng, T. Y., Tu, J., and Kuo, T. T. (1978). Characterization of deoxycytidylate methyltransferase in Xanthomonas oryzae infected with bacteriophage Xp12. Eur. J. Biochem. 87, 29-36. doi: 10.1111/j.1432-1033.1978.tb12348.x

Fleischman, R. A., Cambell, J. L., and Richardson, C. C. (1976). Modification and restriction of T-even bacteriophages. In vitro degradation of deoxyribonucleic acid containing 5-hydroxymethylctosine. J. Biol. Chem. 251, 1561-1570.

Flusberg, B. A., Webster, D. R., Lee, J. H., Travers, K. J., Olivares, E. C., Clark, T. A., et al. (2010). Direct detection of DNA methylation during singlemolecule, real-time sequencing. Nat. Methods 7, 461-465. doi: 10.1038/nmeth. 1459

Forti, F., Roach, D. R., Cafora, M., Pasini, M. E., Horner, D. S., Fiscarelli, E. V., et al. (2018). Design of a broad-range bacteriophage cocktail that reduces pseudomonas aeruginosa biofilms and treats acute infections in two animal models. Antimicrob. Agents Chemother. 62:e2573-17. doi: 10.1128/AAC. 02573-17

Gold, L. M., and Schweiger, M. (1969). Synthesis of phage-specific alpha- and betaglucosyl transferases directed by T-even DNA in vitro. Proc. Natl. Acad. Sci. U.S.A. 62 , 892-898. doi: 10.1073/pnas.62.3.892

Greene, J. R., Morrissey, L. M., and Geiduschek, E. P. (1986). DNA binding by the bacteriophage SPO1-encoded type II DNA-binding protein, transcription factor 1. Site-specific binding requires 5-hydroxymethyluracil-containing DNA. J. Biol. Chem. 261, 12828-12833.

Hattman, S. (1979). Unusual modification of bacteriophage Mu DNA. J. Virol. 32, $468-475$.

He, X., Hull, V., Thomas, J. A., Fu, X., Gidwani, S., Gupta, Y. K., et al. (2015). Expression and purification of a single-chain Type IV restriction enzyme Eco94GmrSD and determination of its substrate preference. Sci. Rep. 5: 9747. doi: $10.1038 /$ srep09747

Heitman, J., and Model, P. (1987). Site-specific methylases induce the SOS DNA repair response in Escherichia coli. J. Bacteriol. 169, 3243-3250. doi: 10.1128/jb. 169.7.3243-3250.1987

Hoet, P. P., Coene, M. M., and Cocito, C. G. (1992). Replication cycle of Bacillus subtilis hydroxymethyluracil-containing phages. Annu. Rev. Microbiol. 46, 95116. doi: 10.1146/annurev.mi.46.100192.000523

Hoskisson, P. A., Sumby, P., and Smith, M. C. (2015). The phage growth limitation system in Streptomyces coelicolor A(3)2 is a toxin/antitoxin system, comprising enzymes with DNA methyltransferase, protein kinase and ATPase activity. Virology 477, 100-109. doi: 10.1016/j.virol.2014.12.036

Huang, L. H., Farnet, C. M., Ehrlich, K. C., and Ehrlich, M. (1982). Digestion of highly modified bacteriophage DNA by restriction endonucleases. Nucleic Acids Res. 10, 1579-1591. doi: 10.1093/nar/10.5.1579

Iyer, L. M., Zhang, D., Burroughs, A. M., and Aravind, L. (2013). Computational identification of novel biochemical systems involved in oxidation, glycosylation and other complex modifications of bases in DNA. Nucleic Acids Res. 41, 7635-7655. doi: 10.1093/nar/gkt573

Kelln, R. A., and Warren, R. A. (1973). Studies on the biosynthesis of alpha-putrescinylthymine in bacteriophage phi W-14-infected Pseudomonas acidovorans. J. Virol. 12, 1427-1433.

Kisiala, M., Copelas, A., Czapinska, H., Xu, S. Y., and Bochtler, M. (2018). Crystal structure of the modification-dependent SRA-HNH endonuclease TagI. Nucleic Acids Res. 46, 10489-10503. doi: 10.1093/nar/gky781

Kropinski, A. M., Bose, R. J., and Warren, R. A. (1973). 5-(4Aminobutylaminomethyl)uracil, an unusual pyrimidine from the deoxyribonucleic acid of bacteriophage phiW-14. Biochemistry 12, 151-157. doi: 10.1021/bi00725a025

Kruger, D. H., and Bickle, T. A. (1983). Bacteriophage survival: multiple mechanisms for avoiding the deoxyribonucleic acid restriction systems of their hosts. Microbiol. Rev. 47, 345-360.

Kulikov, E. E., Golomidova, A. K., Letarova, M. A., Kostryukova, E. S., Zelenin, A. S., Prokhorov, N. S., et al. (2014). Genomic sequencing and biological characteristics of a novel Escherichia coli bacteriophage 9g, a putative representative of a new Siphoviridae genus. Viruses 6, 5077-5092. doi: 10.3390/ v6125077

Landy, A., Ruedisueli, E., Robinson, L., Foeller, C., and Ross, W. (1974). Digestion of deoxyribonucleic acids from bacteriophage T7, lambda, and Phi80h with site-specific nucleases from Hemophilus influenzae strain Rc and strain Rd. Biochemistry 13, 2134-2142. doi: 10.1021/bi00707a022
Lee, Y. J., Dai, N., Walsh, S. E., Muller, S., Fraser, M. E., and Kauffman, K. M. (2018). Identification and biosynthesis of thymidine hypermodifications in the genomic DNA of widespread bacterial viruses. Proc. Natl. Acad. Sci. U.S.A. 115, E3116-E3125. doi: 10.1073/pnas.1714812115

Luria, S. E. (1953). Host-induced modifications of viruses. Cold Spring Harbor Symp. Quant. Biol. 18, 237-244. doi: 10.1101/SQB.1953.018.01.034

Luria, S. E., and Human, M. L. (1952). A nonhereditary, host-induced variation of bacterial viruses. J. Bacteriol. 64, 557-569.

Maltman, K. L., Neuhard, J., Lewis, H. A., and Warren, R. A. (1980). Synthesis of thymine and alpha-putrescinylthymine in bacteriophage phi W-14-infected Pseudomonas acidovorans. J. Virol. 34, 354-359.

Matsuoka, S., Asai, K., and Sadaie, Y. (2005). Restriction and modification of SP10 phage by BsuM of Bacillus subtilis Marburg. FEMS Microbiol. Lett. 244, 335-339. doi: 10.1016/j.femsle.2005.02.006

Miller, P. B., Wakarchuk, W. W., and Warren, R. A. (1985). Alphaputrescinylthymine and the sensitivity of bacteriophage Phi W-14 DNA to restriction endonucleases. Nucleic Acids Res. 13, 2559-2568. doi: 10.1093/nar/ 13.7.2559

Mulligan, E. A., and Dunn, J. J. (2008). Cloning, purification and initial characterization of E. coli McrA, a putative 5-methylcytosine-specific nuclease. Protein Exp. Purif. 62, 98-103. doi: 10.1016/j.pep.2008.06.016

Murray, I. A., Morgan, R. D., Luyten, Y., Fomenkov, A., Corrêa, IR Jr, Dai, N., et al. (2018). The non-specific adenine DNA methyltransferase M.EcoGII. Nucleic Acids Res. 46, 840-848. doi: 10.1093/nar/gkx1191

Neuhard, J., Maltman, K. L., and Warren, R. A. (1980). Bacteriophage phi W14-infected Pseudomonas acidovorans synthesizes hydroxymethyldeoxyuridine triphosphate. J. Virol. 34, 347-353.

Pingoud, A., Wilson, G. G., and Wende, W. (2016). Type II restriction endonucleases - a historical perspective and more. Nucleic Acids Res. 44:8011. doi: 10.1093/nar/gkw513

Raleigh, E. A., Trimarchi, R., and Revel, H. (1989). Genetic and physical mapping of the mcrA $(\mathrm{rglA})$ and $\mathrm{mcrB}(\mathrm{rglB})$ loci of Escherichia coli K-12. Genetics 122, 279-296.

Rifat, D., Wright, N. T., Varney, K. M., Weber, D. J., and Black, L. W. (2008). Restriction endonuclease inhibitor IPI* of bacteriophage T4: a novel structure for a dedicated target. J. Mol. Biol. 375, 720-734. doi: 10.1016/j.jmb.2007. 10.064

Roberts, R. J., Belfort, M., Bestor, T., Bhagwat, A. S., Bickle, T. A., Bitinaite, J., et al. (2003). A nomenclature for restriction enzymes, DNA methyltransferases, homing endonucleases and their genes. Nucleic Acids Res. 31, 1805-1812. doi: 10.1093/nar/gkg274

Robinson, C. R., and Sligar, S. G. (1993). Molecular recognition mediated by bound water. A mechanism for star activity of the restriction endonuclease EcoRI. J. Mol. Biol. 234, 302-306. doi: 10.1006/jmbi.1993.1586

Sambrook, J., Fritsch, E. F., and Maniatis, T. (1989). Molecular Cloning, A Laboratory Manual. Cold Spring Harbor, NY: Cold Spring Harbor Laboratory Press.

Sawaya, M. R., Zhu, Z., Mersha, F., Chan, S. H., Dabur, R., Xu, S. Y., et al. (2013). Crystal structure of the restriction-modification system control element C.Bcll and mapping of its binding site. Structure 13, 1837-1847. doi: 10.1016/j.str. 2005.08.017

Schlagman, S. L., and Hattman, S. (1983). Molecular cloning of a functional dam+ gene coding for phage T4 DNA adenine methylase. Gene 22, 139-156. doi: 10.1016/0378-1119(83)90098-7

Schumann, J., Willert, J., Wild, C., Waler, J., and Trautner, T. A. (1995). M.BssHII: $a$ new multispecific C5-DNA-methyltransferase. Gene 157, 103-104. doi: 10.1016/ 0378-1119(95)00723-J

Scraba, D. G., Bradley, R. D., Leyritz-Wills, M., and Warren, R. A. (1983). Bacteriophage phi W-14: the contribution of covalently bound putrescine to DNA packing in the phage head. Virology 124, 152-160. doi: 10.1016/00426822(83)90298-2

Smith, H. O., and Wilcox, K. W. (1970). A restriction enzyme from Hemophilus influenzae. I. Purification and general properties. J. Mol. Biol. 51, 379-391. doi: 10.1016/0022-2836(70)90149-X

Sternberg, N., and Coulby, J. (1990). Cleavage of the bacteriophage P1 packaging site (pac) is regulated by adenine methylation. Proc. Natl. Acad. Sci. U.S.A. 87, 8070-8074. doi: 10.1073/pnas.87.20.8070 
Stewart, C. R., Casjens, S. R., Cresawn, S. G., Houtz, J. M., Smith, A. L., Ford, M. E., et al. (2009). The genome of Bacillus subtilis bacteriophage SPO1. J. Mol. Biol. 388, 48-70. doi: 10.1016/j.jmb.2009.03.009

Stoddard, B., and Belfort, M. (2010). Social networking between mobile introns and their host genes. Mol. Microbiol. 78, 1-4. doi: 10.1111/j.1365-2958.2010.07217.x

Tao, T., and Blumenthal, R. M. (1992). Sequence and characterization of pvuIIR, the PvuII endonuclease gene, and of pvuIIC, its regulatory gene. J. Bacteriol. 174, 3395-3398. doi: 10.1128/jb.174.10.3395-3398.1992

Thiaville, J. J., Kellner, S. M., Yuan, Y., Hutinet, G., Thiaville, P. C., Jumpathong, W., et al. (2016). Novel genomic island modifies DNA with 7deazaguanine derivatives. Proc. Natl. Acad. Sci. U.S.A. 113, E1452-E1459. doi: 10.1073/pnas.1518570113

Tsai, R., Correa, I. R., Xu, M. Y., and Xu, S. Y. (2017). Restriction and modification of deoxyarchaeosine (dG+)-containing phage 9 g DNA. Sci. Rep. 7:8348. doi: 10.1038/s41598-017-08864-4

Ulbert, S., Eide, L., Seeberg, E., Borst, P., and Base, J. (2004). found in nuclear DNA of Trypanosoma brucei, is not a target for DNA glycosylases. DNA Repair. 3, 145-154. doi: 10.1016/j.dnarep.2003.10.009

Vasu, K., Nagamalleswari, E., Zahran, M., Imhof, P., Xu, S. Y., Zhu, Z., et al. (2013). Increasing cleavage specificity and activity of restriction endonuclease KpnI. Nucleic Acids Res. 41, 9812-9824. doi: 10.1093/nar/gkt734

Vilpo, J. A., and Vilpo, L. M. (1995). Restriction, methylation and ligation of 5 hydroxymethyluracil-containing DNA. Mutat. Res. 316, 123-131. doi: 10.1016/ 0921-8734(95)90005-5

Vincze, T., Posfai, J., and Roberts, R. J. (2003). NEBcutter: a program to cleave DNA with restriction enzymes. Nucleic Acids Res. 31, 3688-3691. doi: 10.1093/ nar/gkg526

Weigele, P., and Raleigh, E. A. (2016). Biosynthesis and function of modified bases in bacteria and their viruses. Chem. Rev. 116, 12655-12687. doi: 10.1021/acs. chemrev.6b00114

Xu, S. Y., Klein, P., Degtyarev, S., and Roberts, R. J. (2016). Expression and purification of the modification-dependent restriction enzyme BisI and its homologous enzymes. Sci. Rep. 6:28579. doi: 10.1038/srep28579
Xu, S. Y., Nugent, R. L., Kasamkattil, J., Fomenkov, A., Gupta, Y., Aggarwal, A., et al. (1992). Characterization of type II and III restriction-modification systems from Bacillus cereus strains ATCC 10987 and ATCC 14579. J. Bacteriol. 194, 49-60. doi: 10.1128/JB.06248-11

Xu, S.-Y., Xiao, J.-P., Posfai, J., Maunus, R., and Benner, J. (1997). Cloning of the BssHII restriction-modification system in Escherichia coli: BssHII methyltransferase contains circularly permuted cytosine-5 methyltransferase motifs. Nucleic Acids Res. 25, 3991-3994. doi: 10.1093/nar/25.20. 3991

Yu, Z., Genest, P. A., ter Riet, B., Sweeney, K., DiPaolo, C., Kieft, R., et al. (2007). The protein that binds to DNA base $\mathrm{J}$ in trypanosomatids has features of a thymidine hydroxylase. Nucleic Acids Res. 35, 2107-2115. doi: 10.1093/nar/ gkm049

Yuan, Y., Hutinet, G., Valera, J. G., Hu, J., Hillebrand, R., Gustafson, A., et al. (2018). Identification of the minimal bacterial 2'-deoxy-7-amido-7deazaguanine synthesis machinery. Mol. Microbiol. 110, 469-483. doi: 10.1111/ mmi.14113

Conflict of Interest Statement: Y-JL, M-QX, IC, PW, and S-YX are employees of New England Biolabs, Inc. New England Biolabs commercializes reagents for molecular biological applications.

The remaining authors declare that the research was conducted in the absence of any commercial or financial relationships that could be construed as a potential conflict of interest.

Copyright (c) 2019 Flodman, Tsai, Xu, Corrêa, Copelas, Lee, Xu, Weigele and Xu. This is an open-access article distributed under the terms of the Creative Commons Attribution License (CC BY). The use, distribution or reproduction in other forums is permitted, provided the original author(s) and the copyright owner(s) are credited and that the original publication in this journal is cited, in accordance with accepted academic practice. No use, distribution or reproduction is permitted which does not comply with these terms. 